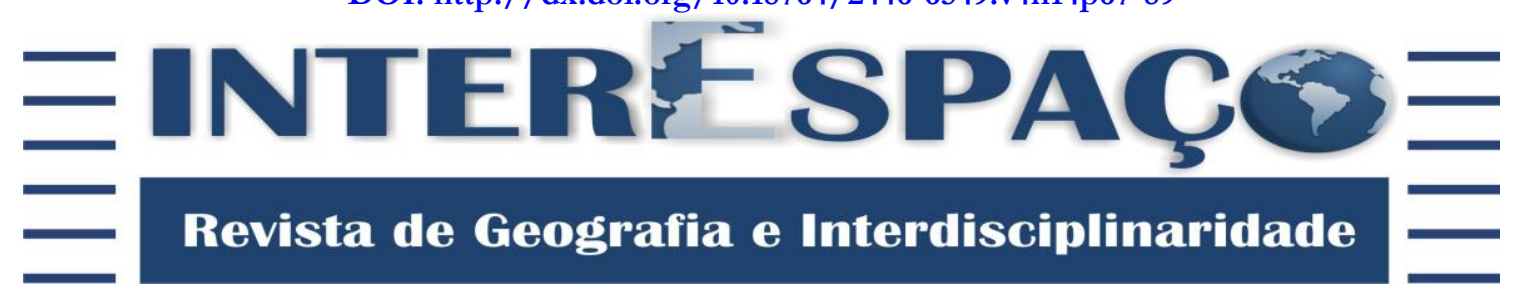

\title{
PLANEJAMENTO AMBIENTAL COSTEIRO NO BRASIL: Um olhar crítico sobre o Projeto Orla
}

\author{
COASTAL ENVIRONMENT PLAN IN BRAZIL: a critical analysis of the Projeto \\ Orla
}

\section{PLANEAMENTO AMBIENTAL COSTEIRO EN BRASIL: una mirada crítica sobre el Proyecto Orla}

\author{
Maria Bonfim Casemiro \\ Mestre em Geografia pela Universidade Estadual do Ceará - UECE. \\ mariabonfimc@gmail.com

\section{Otávio Augusto de Oliveira Lima Barra} \\ Doutorando em Geografia pela Universidade Estadual do Ceará - UECE. \\ otavioaolbarra@gmail.com
}

Fábio Perdigão Vasconcelos

Pós-doutor em Geografia e Doutor em Ciências da Terra pela Universidade de Nantes (França).

Professor do Programa de Pós-graduação em Geografia da Universidade Estadual do Ceará -

$$
\text { UECE. }
$$

fabioperdigao@gmail.com

\section{Fábio de Oliveira Matos}

Doutor em Geografia pela Universidade Federal do Ceará - UFC. Professor Adjunto do Instituto de Ciências do Mar (Labomar) e dos Programas de Pós-graduação em Geografia e Ciências

\section{Marinhas Tropicais da UFC.}

fabiomoria@yahoo.com.br

Recebido para avaliação em 15/06/2018; Aceito para publicação em 11/09/2018.

\section{RESUMO}

O presente trabalho pretende contribuir para a análise do planejamento ambiental costeiro brasileiro a partir de um olhar crítico sobre o Projeto Orla. Compreendendo que as áreas costeiras são ambientes dinâmicos e fortemente instáveis, analisar as ferramentas de gestão ambiental que norteiam o planejamento integrado das áreas litorais no território brasileiro torna-se fundamental. Assim, este artigo tem por objetivo analisar o planejamento ambiental costeiro a partir das orientações do Projeto Orla. Com relação aos aspectos metodológicos, trata-se de uma pesquisa de cunho documental, sobretudo na análise e exploração da legislação costeira enquanto proposta de minimização dos problemas ambientais. Os resultados revelaram que as leis de gerenciamento costeiro constituem importantes instrumentos de orientação para as ações e funcionam como suportes ao poder público. É necessária a promoção de políticas de gestão do desenvolvimento, em longo prazo, que partam do poder público, visando não apenas o desenvolvimento econômico de determinada região, mas buscando sempre o envolvimento da população nesse processo. Assim, uma gestão participativa de forma mais integrada possível buscando sempre envolver todas as dimensões geográficas, desde os municípios, os estados e o país.

Palavras-chave: Gestão Ambiental; Meio Ambiente; Poder Público. 
| Maria Bonfim Casemiro | Otávio Augusto de Oliveira Lima Barra | Fábio Perdigão Vasconcelos | |Fábio de Oliveira Matos |

\begin{abstract}
The present paper aims to contribute to the analysis of the Brazilian coastal environment planning by casting a critical glance at the Projeto Orla. In understanding that the coastal areas are dynamic and highly unstable environments, the examination of the tools for environmental management which guide the integrated planning of the Brazilian coastal areas becomes fundamental. Thus, in the present paper, the goal is to examine the coastal environment planning according to the directions written in the Projeto Orla. Regarding methodological aspects, it is documentary research, especially in the analysis and exploration of the legislation regarding the coastal areas which aim to minimize the environmental problems. The results have revealed that laws for coastal management are important guiding tools for the actions and they function as supports for the public authorities. It is necessary that there be the promotion of policies for the management of development by the public authorities, in the long term, intending to not only the economic development of a particular region but also always seeking to involve people in this process. Thus, participatory management in a more integrated way, always seeking to involve all the geographic dimensions, from cities, states, to the country.
\end{abstract}

Keywords: Environment Management; Environment; Public Authorities.

\title{
RESUMEN
}

El presente trabajo pretende contribuir para el análisis de la planificación ambiental costera brasileño a partir de una mirada crítica sobre el Proyecto Orla. Sabiendo que las áreas costeras son entornos dinámicos y muy inestable, analizar las herramientas de gestión ambiental que orientan el planeamiento integrado de las áreas costeras en el territorio brasileño se vuelve fundamental. Así, el presente trabajo tiene por objetivo analizar el planeamento ambiental costero a partir de las orientaciones del Proyecto Orla. Con respecto a los aspectos metodológicos, se trata de una investigación de cuño documental, sobre todo en el análisis y la explotación de la legislación costera como propuesta de minimización de los problemas ambientales. Los resultados revelaron que las leyes de gestión costera son importantes instrumentos de orientación para las acciones y funcionan como soporte al poder público. Es necesario promover políticas de gestión de desenvolvimento, a largo plazo, que salen del poder público, con el propósito de no sólo el desarrollo económico de una determinada región, pero buscando siempre la participación de la población en ese proceso. Así, una gestión participativa de forma más integrada posible siempre tratando de involucrar a todas las dimensiones geográficas, desde los municipios, los estados y el país.

Palabras clave: Gestión Ambiental; Medio Ambiente; Poder Público.

\section{INTRODUÇÃO}

A partir das três últimas décadas do século passado, os problemas ambientais ganharam destaque e passaram a ser tratados com mais atenção. Assim, a solução encontrada para pensar novas formas de desenvolvimento com menor agressão à natureza e, consequentemente, uma minimização de tais problemas surgiu com a adoção da abordagem sistêmica, esta pautada na gestão integrada do meio ambiente, principalmente os ambientes litorâneos (VASCONCELOS, 2005).

Nesse sentido, os programas de gestão costeira incorporaram essa discussão e passaram a orientar políticas desenvolvidas para o meio ambiente sob uma perspectiva de sustentabilidade, ou seja, que o meio ambiente fosse considerado para além do ponto de vista econômico como forma de garantir um meio equilibrado para as futuras gerações. A 
| Planejamento ambiental costeiro no Brasil: um olhar crítico sobre o Projeto Orla |

| Maria Bonfim Casemiro | Otávio Augusto de Oliveira Lima Barra | Fábio Perdigão Vasconcelos | |Fábio de Oliveira Matos |

intenção primordial de tais programas é apresentar uma síntese das principais normas regulatórias, os projetos, planos e regulamentações pertinentes que controlam o uso e a ocupação do solo e as atividades humanas da zona costeira.

Davidson-Arnott (2010) chama a atenção para o fato de que o problema ambiental costeiro, muitas vezes, está ligado ao uso e ocupação desse espaço, uma vez que a maioria das atividades industriais desenvolvidas no país se dá no referido espaço e representam uma ameaça ambiental, tanto física quanto biológica. Através da poluição, dos processos de assoreamento e dragagem, das atividades de aterro e uma série de outras atividades que alteram a forma e os processos naturais sobre o ecossistema costeiro.

Assim, o ato de gerenciar algo implica em gerir conflitos acirrados, sobretudo nas zonas costeiras, justamente por serem áreas onde coexistem interesses diversos, além de envolverem grandes contingentes populacionais. Logo, a zona costeira torna-se o lugar de constante pressão populacional e econômica. É, também, fonte de recursos naturais utilizados pelas populações humanas, de tal forma que a combinação desses fatores origina conflitos diversos de usos e interesses (VASCONCELOS, 2005). Assim, o presente trabalho tem por objetivo geral analisar o planejamento ambiental costeiro, a partir das orientações do Projeto Orla. Tal projeto, apoiado por outros instrumentos de ordenamento territorial, propõe o desenvolvimento de ações de planejamento compartilhado entre as três instâncias governamentais; a Procuradoria Pública do estado e da União; associadas com a participação da sociedade, buscando sempre o aperfeiçoamento das normas que auxiliem a gestão e a minimização dos conflitos de uso e ocupação da orla marítima (BRASIL, 2006).

Notadamente, o levantamento empreendido sobre os instrumentos legais, associados à gestão costeira, busca contemplar os principais documentos incidentes sobre a região litorânea no seu aspecto federativo. Com o intuito de almejar os objetivos traçados, a reflexão teórica proposta foi norteada por ampla busca bibliográfica. A imersão nas fontes primárias que versassem sobre as temáticas da gestão pedagógica e educação ambiental foram fundamentais para o desenvolvimento do manuscrito. Foram utilizadas fontes diversificadas, partindo desde o levantamento de investigações científicas empreendidas nessa seara (retrospectivas ou contemporâneas), bem como fontes de "primeira mão" (GERHARDT et al., 2009, p. 69), notadamente os documentos sem tratamento analítico, como documentos oficiais, legislações e dados estatísticos.

A fim de se verificar os marcos legais da gestão costeira no país, foi abordada consulta a legislação brasileira que trata, direta ou indiretamente, sobre a temática. Dessa forma, os documentos elencados foram: a) a Constituição Federal de 1998; b) a Lei 
| Maria Bonfim Casemiro | Otávio Augusto de Oliveira Lima Barra | Fábio Perdigão Vasconcelos | |Fábio de Oliveira Matos |

7.661/88, que institui o Plano Nacional de Gerenciamento Costeiro; e c) o Projeto de Gestão Integrada da Zona Marítima.

Tais conjuntos de ferramentas de gestão costeira consistem em uma tentativa de mudança de comportamento em relação à ocupação da zona costeira.

A investigação das políticas elaboradas para a zona costeira é fundamental, principalmente para aquelas propostas de planejamento e gestão que atuam em escalas que possibilitem maior detalhe de atuação, como por exemplo, a esfera municipal trabalhada pelo Projeto Orla; pois através da compreensão das propostas e das diversas políticas ambientais desenvolvidas ao longo dos últimos anos será possível chegar a uma conclusão no que se refere à efetividade das mesmas, ou seja, se realmente funcionaram, se cumpriram com o que propunham a solucionar ou se deixaram a desejar. Essas políticas devem partir sempre do pressuposto de que se trata de um ambiente extremamente dinâmico. Logo, uma área suscetível a modificações deve ser estudada de forma integrada e sistêmica, seja em seus aspectos ambientais, econômicos e/ou sociais.

\section{LEGISLAÇÕES PERTINENTES}

\section{Direito Ambiental e planejamento costeiro brasileiro}

A priori, cabe destacar que só recentemente o meio ambiente foi, de fato, estudado enquanto objeto jurídico, voltado para a preservação e proteção. Sendo assim, é importante entender sua abordagem constitucional para perceber como é feita a proteção ambiental, que legitima o direito a um meio ambiente equilibrado, mas que também reconhece constitucionalmente o direito social estabelecido pela Constituição Federal de 1988 (ALMEIDA, 2006).

Tratar dos fundamentos que norteiam as políticas públicas e o direito ambiental requer entender, inicialmente, o contexto histórico ambiental ao longo do tempo. O direito ambiental surge a partir da imposição de limites e regras para diminuir a degradação ambiental que estava posta. O surgimento desse direito passa a exigir dos Estados e seus entes - União, Estados e Municípios - que os limites e as normas estabelecidas fossem cumpridas, tornando necessária a implantação de políticas públicas voltadas à sociedade, com o objetivo de orientá-las à proteção do meio ambiente, visando assim à diminuição dos impactos a ele causados (BRASIL, 1981).

O marco internacional do direito ambiental se deu a partir da Conferência das Nações Unidas sobre o Meio Ambiente, celebrada em Estocolmo, no ano de 1972. 
| Planejamento ambiental costeiro no Brasil: um olhar crítico sobre o Projeto Orla |

| Maria Bonfim Casemiro | Otávio Augusto de Oliveira Lima Barra | Fábio Perdigão Vasconcelos | |Fábio de Oliveira Matos |

Conforme Pilati, Dantas e Leite (2011), nessa conferência o meio ambiente foi tratado pela primeira vez como um bem jurídico, algo a ser protegido, independentemente, dos interesses desenvolvimentistas do homem, sob o risco de um colapso, em que a natureza não mais serviria aos interesses do homem. Consistiu, assim, um primeiro passo para uma melhor conscientização ambiental.

Essas discussões, retomadas em 1987, a partir do Relatório de Brundtland, alertava para a necessidade de um novo modelo de desenvolvimento sustentável que viesse a satisfazer as necessidades das presentes gerações sem comprometer a capacidade das próximas gerações (BRASIL, 1988). Em 1992, com a Conferência das Nações Unidas sobre o Meio Ambiente e o Desenvolvimento (CNUMAD), mais conhecida como Rio 92, foram reforçadas as orientações de um planejamento baseado na elaboração de métodos de proteção ambiental, justiça social e eficiência econômica.

O principal produto dessa conferência foi um documento com 40 capítulos, denominado Agenda 21 Global. Dentre os documentos elaborados, é preciso salientar o capítulo 17, dedicado, especificamente, à proteção dos oceanos e de todos os tipos de mares. Neste documento, o ambiente marinho (oceanos, mares e zonas costeiras adjacentes) forma um todo integrado e possibilita a existência de vida na Terra, constitui-se também de riqueza, oferecendo possibilidades inúmeras de desenvolvimento sustentável; o documento recomenda ainda a realização de novas práticas econômico-sociais e implementação política (ALMEIDA, 2006).

Como resultado da ECO 92, a Organização das Nações Unidas para a Educação, a Ciência e a Cultura (United Nations Education, Scientific and Cultural Organization - UNESCO) publicou vários documentos objetivando promover o estudo sistêmico da zona costeira, visando a parceria com as comunidades litorâneas de forma a alcançar o desenvolvimento sustentável da área, denominada Gestão Integrada da Zona Costeira (GIZC).

As zonas costeiras são áreas dinâmicas e bastante frágeis, e justamente por ser muito procuradas e valorizadas o surgimento de conflitos torna-se inevitável (ALMEIDA, 2006). Nesse sentido, a gestão eficaz desse espaço faz-se necessária, sendo um grande desafio para o planejamento ambiental costeiro brasileiro. Essa ação torna-se mais complexa quando a gestão passa a ser realizada de forma compartilhada pelos entes federativos, sobretudo na esfera da União, pois, muitas vezes, os interesses são contrários.

Vale destacar aqui a Lei Complementar n. 140, de 8 de dezembro de 2011, art. $1^{\circ}$ embasada nos incisos III, VI e VII do caput e do parágrafo único do art. 23 da Constituição Federal, fixa normas para cooperação entre União, Estados, Distrito Federal e 
| Maria Bonfim Casemiro | Otávio Augusto de Oliveira Lima Barra | Fábio Perdigão Vasconcelos | |Fábio de Oliveira Matos |

Municípios a ser realizado a partir de ações administrativas relacionadas ao âmbito de sua competência, a citada Lei aponta a necessidade de se proteger as paisagens naturais do meio ambiente, bem como o combate à poluição de forma a preservar as florestas, a fauna e a flora do território brasileiro (BRASIL, 2011).

No que tange ao litoral brasileiro, além deste possuir uma grande extensão, nesse espaço há grande pressão populacional; conforme os dados divulgados pelo Instituto Brasileiro de Geografia e Estatística (IBGE) em parceria com a Comissão Interministerial para os Recursos do Mar (CIRM) cerca de 50,7 milhões de pessoas, ou seja, 26,6\% (1/4) dos habitantes do País ocupam áreas predominantemente próximas ao litoral e moram em municípios da zona costeira do país (IBGE, 2011). Os diversos padrões de ocupação humana, de uso do solo e utilização dos recursos naturais, associados à disputa do espaço por lazer, e moradia, fazem com que o surgimento de problemas ambientais e sociais tornese realidade latente, dificultando, assim, o gerenciamento desses lugares.

Esses problemas geralmente são resultantes da implantação de empreendimentos de fortes impactos às estruturas urbanas e ambientais, a exemplo: desmatamento de manguezais; comprometimento das condições dos ecossistemas estuarinos; processos impactantes decorrentes da urbanização desordenada; assentamentos urbanos irregulares e precários (AGRA FILHO, 2006); sobrecarga das redes de saneamento; aterramento de lagoas; poluição dos recursos hídricos superficiais e deposição de resíduos sólidos. O surgimento de tais problemas ambientais, alguns graves e até irreversíveis, exigiu da comunidade científica a elaboração de um arcabouço jurídico em nível mundial. Isso mostrou a necessidade urgente de programas específicos de gestão costeira capazes de adaptarem-se à realidade problemática do planeta, em especial as áreas costeiras.

Salvaguardar o meio ambiente e o ser humano é uma tarefa que exige, necessariamente, um conhecimento transdisciplinar. Nesse sentido, é dever do Estado propor medidas efetivas de sustentabilidade socioambiental, conforme preceitua o caput do artigo 225 da Constituição Federal:

Todos têm direito ao meio ambiente ecologicamente equilibrado, bem de uso comum do povo e essencial à sadia qualidade de vida, impondo-se ao poder público e à coletividade o dever de defendê-lo e preservá-lo para as presentes e futuras gerações (BRASIL, 1988, p. 1).

A legislação deixa claro o direito de todos os indivíduos a um meio ambiente equilibrado e o dever do poder público na preservação, de tal forma que não é um ambiente qualquer, mas aquele que seja saudável e permissível à vida e ao desenvolvimento 
| Maria Bonfim Casemiro | Otávio Augusto de Oliveira Lima Barra | Fábio Perdigão Vasconcelos | |Fábio de Oliveira Matos |

humano, pois esse é o significado da expressão ecologicamente equilibrado citado na Carta Magna. Conforme Moraes (2007), o modelo de gestão da Carta Magna estabelece que o papel a ser exercido pela União consiste nas tarefas de coordenação e supervisão na implantação dos planos e programas, no estímulo e acompanhamento das ações de forma descentralizadas, e a articulação das iniciativas geradas na própria órbita federal. A esfera federal tem por papel de mediar as ações de gestão, envolvendo não somente os governos estaduais e municipais, mas também as universidades - pesquisadores - e as comunidades atingidas pelos programas. O que fica claro a tentativa de realização de uma gestão integrada. O Projeto Orla Marítima insere-se na perspectiva de uma gestão ambiental integrada.

$\mathrm{Na}$ atual Constituição, as praias e os terrenos de marinha e acrescidos são considerados bens e patrimônio da União. A definição de praia, no art. 10 da Constituição, cita esses ambientes como bens de uso comum do povo, que deve ser sempre assegurado seu acesso e em qualquer direção ou sentido, exceto as áreas protegidas por legislação específica ou de interesse nacional (BRASIL, 1988). No inciso $4^{\circ}$ do artigo 225 da Constituição Federal 1988 (CF/88) a zona costeira é definida como patrimônio nacional, área considerada como porção do território brasileiro que merece especial atenção do poder público quanto ao uso dos recursos naturais e a sua ocupação, de forma a assegurar a preservação.

No que se refere ao arranjo institucional brasileiro (Figura 1), a gestão costeira nacional é realizada a partir da orientação do órgão central nacional, exercida pelo Ministério do Meio Ambiente(MMA), no âmbito federal. A supervisão e o apoio a esse órgão é de responsabilidade da Comissão Interministerial para Recursos do Mar (CIRM) e do Grupo de Integração de Gerenciamento Costeiro (GI-GERCO) representado pelos dezessete estados costeiros do país. 
| Maria Bonfim Casemiro | Otávio Augusto de Oliveira Lima Barra | Fábio Perdigão Vasconcelos | |Fábio de Oliveira Matos |

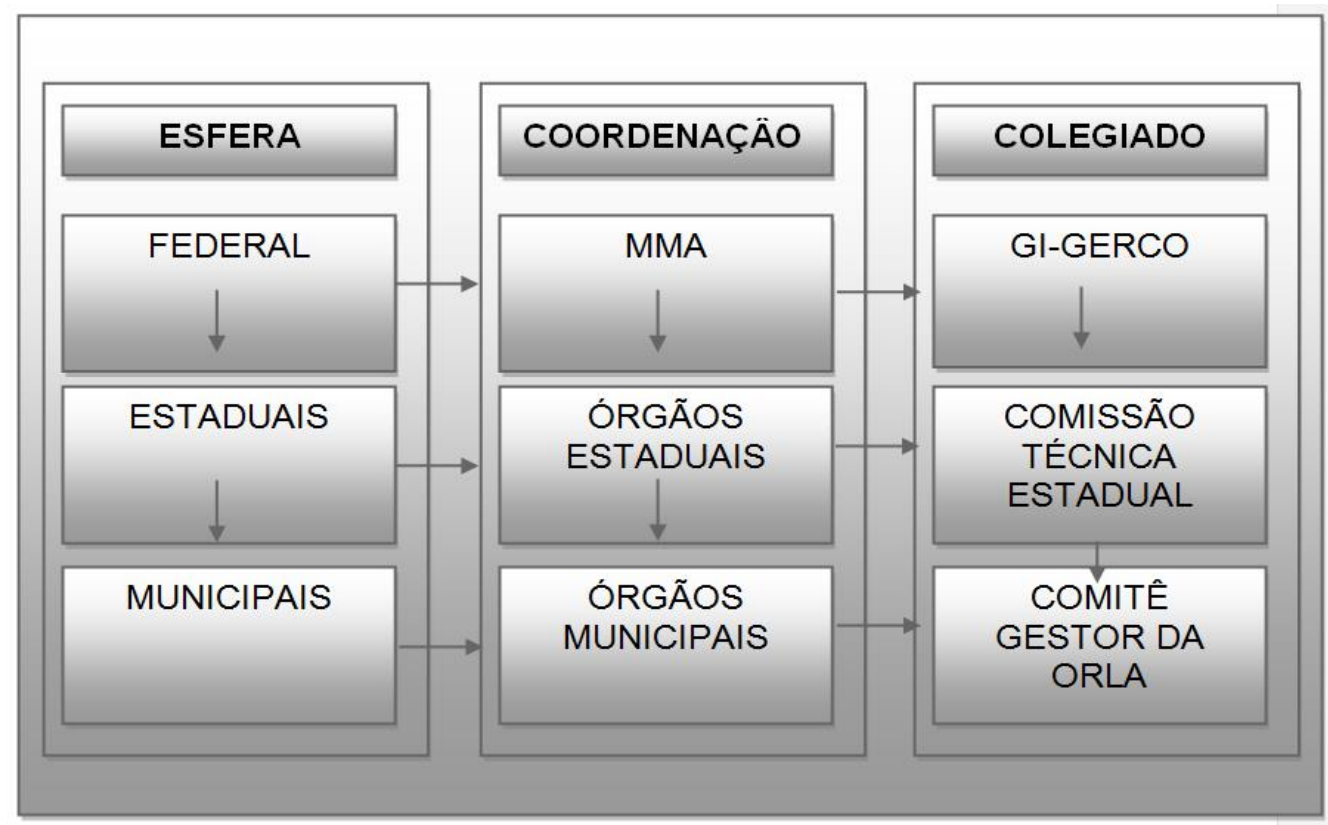

Figura 1 - Arranjo Institucional da Gestão Costeira no Brasil Fonte: Adaptado do MMA (2016).

Nas esferas estaduais, e obedecendo às normas e orientações do Plano Nacional para os ambientes costeiros, existem os coordenadores dos órgãos de cada estado costeiro que têm a responsabilidade de elaborar planos estaduais. Já no âmbito da esfera municipal, a coordenação se dá através dos órgãos de gestão municipal, com apoio do Comitê Gestor da Orla Municipal, enquanto órgão colegiado, sempre obedecendo às normas vigentes das esferas federal e estadual.

\section{Os planos nacionais de gerenciamento costeiro}

O planejamento costeiro brasileiro se deu a partir da orientação de algumas políticas, planos e decretos estabelecidos e aperfeiçoados ao longo dos anos. A Figura 2 destaca os documentos referentes às legislações que tratam sobre essa gestão costeira, ou seja, todo o aparato legal de proteção aos ambientes litorâneos, desde os primórdios de sua implantação, iniciados com a PNRM (Política Nacional para os Recursos do Mar) e a PNRH (Política Nacional de Recursos Hídricos) - políticas essas que conjuntamente com a CF/88 foram basilares para a orientação de todos os outros planejamentos costeiros, perpassando as duas versões do PNGC, do Plano de Ação Federal da Zona Costeira (PAFZC) até os decretos mais recentes no Brasil. 
| Planejamento ambiental costeiro no Brasil: um olhar crítico sobre o Projeto Orla |

| Maria Bonfim Casemiro | Otávio Augusto de Oliveira Lima Barra | Fábio Perdigão Vasconcelos | |Fábio de Oliveira Matos |

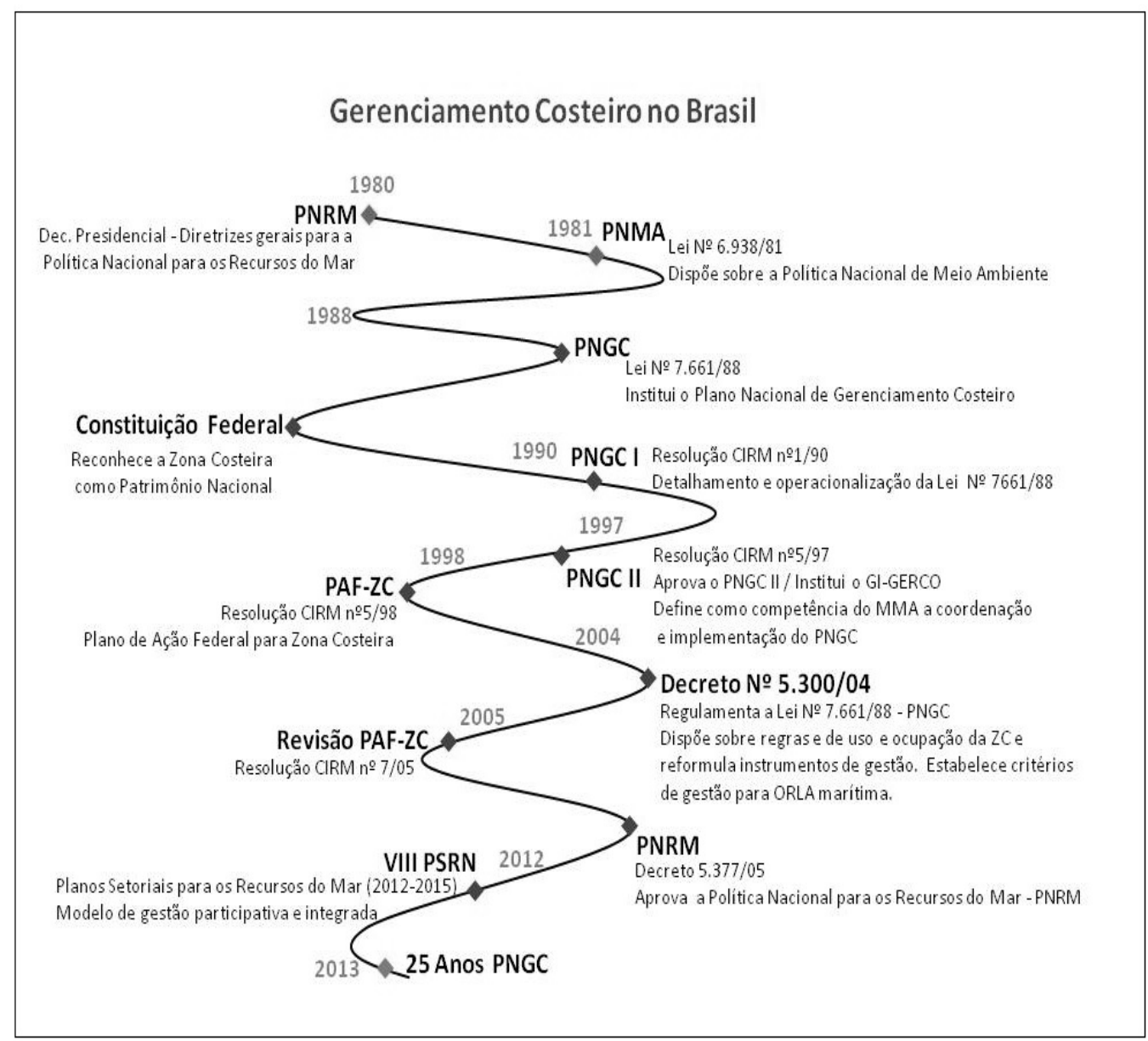

Figura 2 - Percurso legal do gerenciamento costeiro no Brasil Fonte: Ministério do Meio Ambiente - MMA (2017).

A instituição do PNGC I se deu por meio da Lei Federal n ${ }^{\circ} 7.661$, de 16 de maio de 1988, regulamentado pelo Decreto n. 5300, de 7 de dezembro de 2004. O artigo $2^{\circ}$, parágrafo único da referida lei cita a definição de zona costeira como sendo: "o espaço geográfico de interação do ar, do mar e da terra, incluindo seus recursos renováveis ou não, e abrangendo uma faixa marítima e outra terrestre, a serem definidas neste Plano" (BRASIL, 1998, p. 1). Nessa primeira versão o plano focou nas ações individuais dos estados, faltava uma integração entre as esferas administrativas.

O PNGC constitui-se enquanto plano subordinado aos princípios e objetivos da PNMA (Política Nacional do Meio Ambiente) e da PNRM. Segundo a Lei n 7.661/88, art. $2^{\circ}$, o Plano tem como objetivo: “orientar a utilização racional dos recursos na Zona Costeira, de forma a contribuir para elevar a qualidade da vida de sua população, e a proteção do seu patrimônio natural, histórico, étnico e cultural.” (BRASIL, 1981, p. 1). Ele orienta um conjunto de medidas necessárias à gestão da zona costeira, medidas essas embasadas em projetos diversos, como exemplo: educação ambiental, ecoturismo, 
| Maria Bonfim Casemiro | Otávio Augusto de Oliveira Lima Barra | Fábio Perdigão Vasconcelos | |Fábio de Oliveira Matos |

programas de apoio à pesca nos períodos de defeso, dentre outras atividades realizadas de formas integradas ou setoriais.

A versão do PNGC I foi implantada em esforço conjunto entre o governo federal e as esferas estaduais e municipais. Essa versão consistiu em síntese da elaboração de princípios norteadores do gerenciamento costeiro, estabelecendo conceitos, definições, objetivos e diretrizes, dentre outros (BRASIL, 1988). O artigo $4^{\circ}$ da Lei n. 7.661/88 estabelece que o PNGC quando necessário poderá ser atualizado por um Grupo de Coordenação, dirigido pela Secretaria da Comissão Interministerial para os Recursos do Mar (SECIRM), responsável por elaborar uma nova versão. Diante das modificações e as novas demandas surgidas a partir da experiência do programa, as tomadas de novos direcionamentos passaram a ser exigidos (PEREIRA; OLIVEIRA, 2015).

Assim, em 1997, uma nova Resolução - a CIRM nº. 05/97 - aprova o PNGC II e institui o Gerenciamento Costeiro (GERCO), definindo como competência do MMA a coordenação e a implantação do gerenciamento costeiro. Dessa forma, o PNGC II estava diretamente ligado ao GERCO e passou, ao longo de todo o processo de implantação, por ajustes em seu modelo institucional e metodológico, resultado, sobretudo, da experiência proporcionada durante a fase do PNGC I.

Em sua nova versão, o PNGC foi reformulado e reestruturado, sendo feitos alguns ajustes nos campos institucionais e operacionais, visando a sua adequação frente aos problemas. Ele reafirma os instrumentos do programa anterior, centrando-se, principalmente, na parte operacional, reavaliando a metodologia e operacionalizando a parte institucional. Nesta é enfatizada a necessidade da parceria entre o poder público municipal, estadual e federal e a sociedade civil organizada, demonstrando, assim, uma política que valorizasse a integração (PEREIRA; OLIVEIRA, 2015).

No II PNGC a delimitação de zona costeira deixou de ser definida de forma absoluta, ganhando viés político voltado ao planejamento e gestão, sempre passíveis de mudança, considerando os aspectos políticos administrativos e as diversas especificidades de cada município costeiro. Assim, nessa nova versão a questão das escalas ganhou destaque, visando maior articulação e interlocução entre as instâncias governamentais (PEREIRA; OLIVEIRA, 2015).

A inovação elaborada pelo PNGC II foi o GI-GERCO, que tinha como objetivo operacionalizar o PNGC de forma centralizada e participativa, promovendo uma articulação entre as ações federais diretamente influenciadas sobre a zona costeira, a partir 
| Maria Bonfim Casemiro | Otávio Augusto de Oliveira Lima Barra | Fábio Perdigão Vasconcelos | |Fábio de Oliveira Matos |

do Plano de Ação Federal da Zona Costeira (PAF-ZC), este servindo de apoio junto ao PNGC.

De acordo com Moraes (2007), o PAF-ZC tinha por finalidade básica tornar compatível as ações e os objetivos das parcerias, no sentido de acentuar a união das aplicações do PNGC entre as várias instâncias governamentais. A elaboração de uma terceira versão do PNGC já era solicitada pelo referido autor, em que, naquele ano, apontava para a necessidade de revisão e elaboração de uma nova versão do plano. Souza (2009) corrobora com a ideia do autor, afirmando que, à época, era necessária a efetivação de uma versão mais recente do Plano, o PNGC III, o qual deveria substituir o PNGC II. Entretanto, após seis anos, a terceira versão reivindicada ainda não foi concretizada.

Em linhas gerais, o atraso na revisão e na elaboração da terceira versão do PNGC, para alguns estudiosos, tem reflexo na atualidade através do agravamento dos problemas costeiros. Essa nova revisão é necessária, tendo em vista que as orientações do plano em vigor, pela forma como estão postas, não conseguem mais dar conta da realidade dinâmica e da complexidade do ambiente costeiro.

\section{A GIZC como ferramenta de gestão}

A primeira nação a adotar formalmente um Plano Nacional de Gerenciamento Costeiro foram os Estados Unidos, através do Coastal Zone Management Act (Lei do Gerenciamento da Zona Costeira), em 1972. Esse documento citava os conceitos, princípios e os objetivos, no sentido de fornecer orientações. Estas que, posteriormente foram utilizadas por outras nações, particularmente àquelas em desenvolvimento (CICINSAIN KNECHT, 1998).

A gestão costeira integrada consiste na ferramenta de auxílio à mudança de comportamento em relação à ocupação da zona costeira. Em seus estudos sobre o tema, Vasconcelos (2005) cita que esta tem por base o conjunto de medidas fundamentadas no conhecimento científico e na tomada de decisão, a partir de uma forma de pirâmide, partindo de ações tomadas pela base (sociedade) ao topo (poder público). O autor destaca que nessa gestão em que coexistem as atividades humanas e o meio natural, é fundamental a tomada de decisão, pois reforça o papel de parceria entre os diferentes atores.

De maneira geral, conforme Olsen (2003), o processo de efetivação do gerenciamento costeiro integrado proposto se dá fundamentados em um ciclo (Figura 3), a partir de cinco etapas distintas e interligadas que partem inicialmente da identificação e 
| Maria Bonfim Casemiro | Otávio Augusto de Oliveira Lima Barra | Fábio Perdigão Vasconcelos | |Fábio de Oliveira Matos |

análise do problema organizando ações a serem empreendidas para a promoção da gestão costeira. Sequenciado da preparação do programa, definindo a escala de trabalho, separando a área em unidades coerentes de gestão, com as mesmas características. No terceiro momento, vem a adoção formal e o financiamento, é momento de aprovação formal das políticas e planos.

A quarta etapa do processo de efetivação do gerenciamento integrado consiste na implementação do programa, monitorando e interpretando as tendências relacionadas à sociedade e ao ambiente ecossistêmico. Chega-se, assim, a quinta e última fase que consiste na avaliação do programa como um todo, identificando o que deu certo e o que pode ser melhorado; é o momento de documentar os resultados do programa, reavaliando os problemas da gestão, reajustando as prioridades e políticas, percebendo as mudanças sociais e ambientais, de forma que novas questões ou áreas possam ser identificadas para inclusão no programa. Todas as fases passam por constantes ajustes a serem realizados progressivamente e reavaliados em um ciclo repetitivo (OLSEN, 2003).

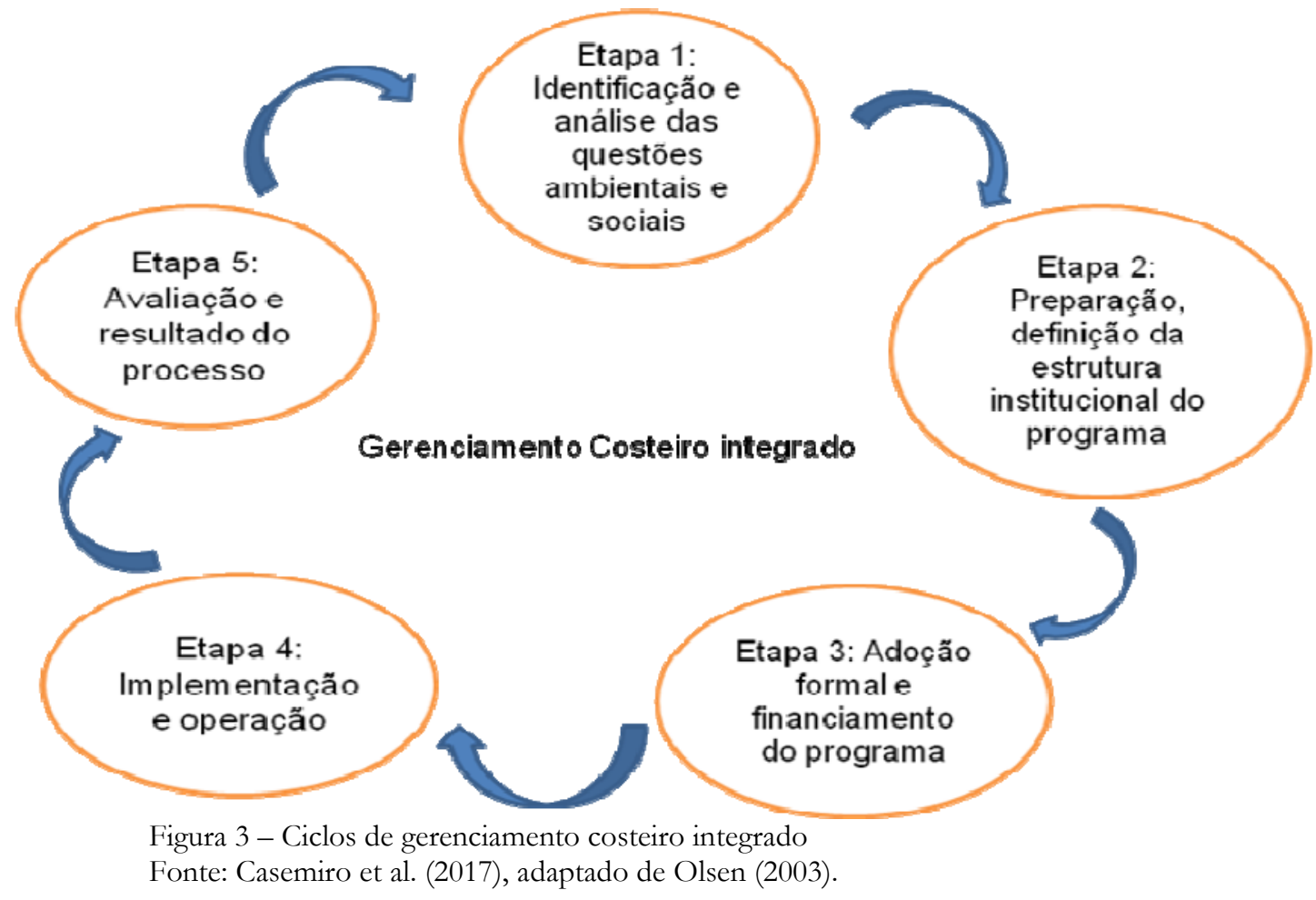

Conforme Polette et al. (2006), um efetivo processo de gestão costeira exige, necessariamente, que haja o fortalecimento de um diálogo e articulação com a sociedade civil, bem como a inclusão dos atores sociais nos diferentes setores envolvidos no processo. Assim, a gestão costeira integrada consiste em uma metodologia estruturada em um ciclo de energia, a partir da formulação, implementação e avaliação de ações políticas, 
| Maria Bonfim Casemiro | Otávio Augusto de Oliveira Lima Barra | Fábio Perdigão Vasconcelos | |Fábio de Oliveira Matos |

em uma sequência de fases que se encontram interconectadas e interdependentes entre diferentes grupos de atividades. Há uma sequência de orientação em que todas as suas etapas devem necessariamente ser seguidas e reavaliadas constantemente, ou seja, há um ciclo constante de planejamento, implementação e avaliação (OLSEN, 2003).

\section{O PROJETO ORLA EM DESTAQUE}

\section{Definições}

Visando ao ordenamento e ao planejamento dessas áreas, surge o Projeto Orla, inserido no âmbito do GI-GERCO e do PAF-ZC. O Projeto Orla constitui-se numa proposição de planejamento de gestão territorial, elaborado em 2002. Conforme a Lei n. 9.636, de 15 de maio de 1998, a orla é de exclusividade da União. O art. 40 cita que a Secretaria de Patrimônio da União (SPU) é a responsável pela realização de concessões, locações, arrendamentos e cessões de imóveis de propriedade da União (BRASIL, 1998).

Entretanto, apesar dessa exclusividade o decreto n. 5.300/2004 regulamentando a Lei $n^{\circ}$. 7.661/88 inovou no sentido de apresentar a orla como um espaço de gestão compartilhado com os municípios. Assim, houve uma descentralização de ações ficando a cargo do Projeto Orla e de outros instrumentos de ordenamento territorial, através de ações de planejamento compartilhado entre as três instâncias governamentais, associadas à participação da sociedade. O aperfeiçoamento das normas no auxílio à gestão, bem como a minimização dos conflitos da orla marítima (BRASIL, 2006).

O Projeto de Gestão Integrada da Orla Marítima - Projeto Orla - constitui-se de um projeto articulado com a organização institucional entre as três instâncias governamentais, sempre na busca por diálogos constantes com os diversos atores sociais, por meio de fóruns intermediados pelo poder público municipal. Esse projeto trabalha com um espaço específico que é a orla, um espaço restrito da zona costeira.

Convém destacar a definição de orla marítima (Figura 4) estabelecida no Decreto Federal nº. 5.300/2004, publicado no Diário Oficial da União (DOU), que regulamenta a Lei $n^{\circ}$. 7.661/88 que institui o Plano Nacional de Gerenciamento Costeiro (PNGC) e dispõe sobre as regras de uso e ocupação da zona costeira. De acordo com o referido Decreto, Art. 22, a orla marítima é definida como uma "faixa contida na zona costeira, de largura variável, compreendendo uma porção marítima e outra terrestre, caracterizada pela interface entre a terra e o mar" (Brasil, 2004, p. 1). 
| Maria Bonfim Casemiro | Otávio Augusto de Oliveira Lima Barra | Fábio Perdigão Vasconcelos | |Fábio de Oliveira Matos |

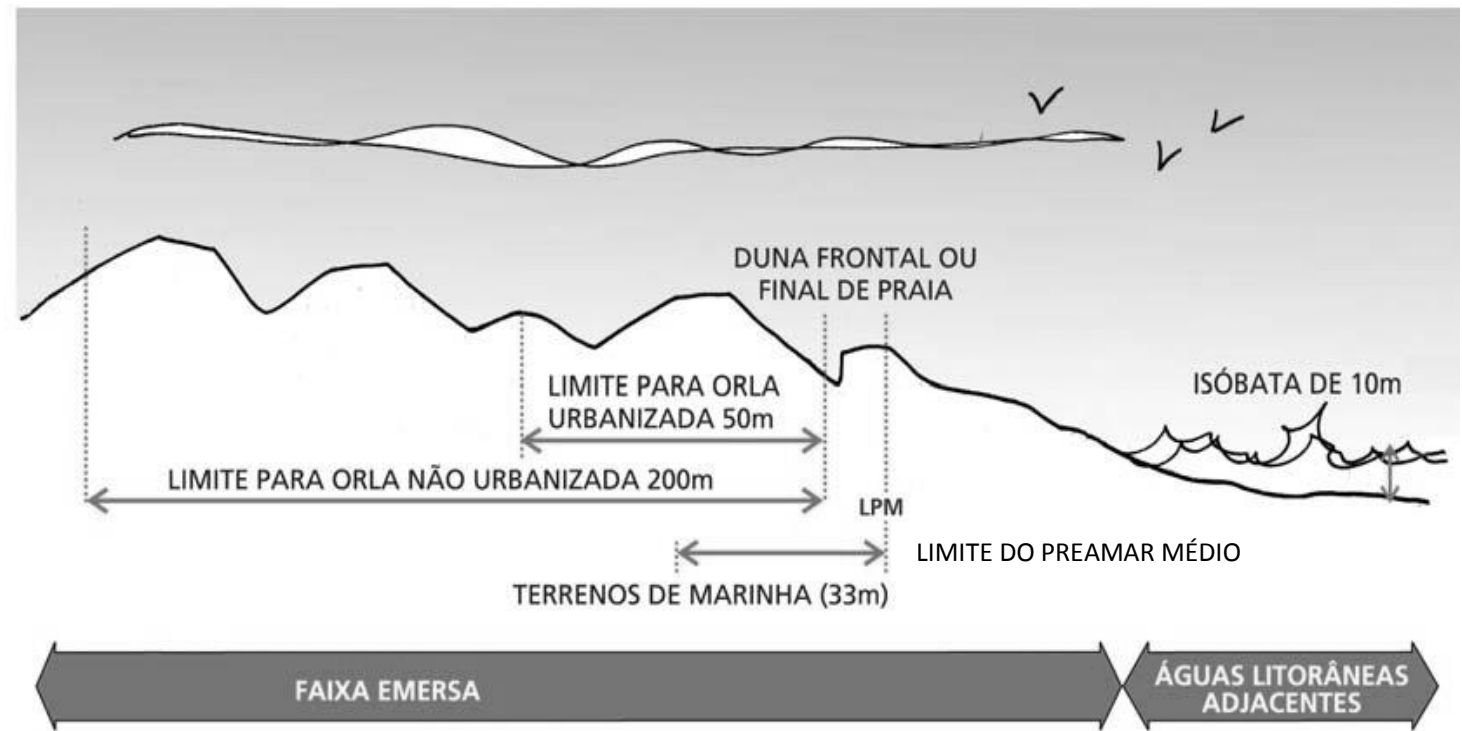

Figura 4 - Definição e delimitação de orla

Fonte: Brasil (2006) adaptada.

Assim, para fins de delimitação a orla é caracterizada, de acordo com o Projeto, como sendo uma orla urbanizada, estabelecendo o limite a partir da Linha de Preamar (LPM) até os $50 \mathrm{~m}$ na área terrestre para as áreas em que já exista uma urbanização consolidada. Para a orla não urbanizada a LPM estabelece o limite no continente de $200 \mathrm{~m}$ em áreas de urbanização não consolidadas (BRASIL, 2004). Logo, é um espaço de múltiplos usos e sujeito a sérios conflitos socioambientais como resultado do seu processo de uso e ocupação intenso, logo, é uma área que exige um planejamento (MORAES, 2007).

\section{Objetivos}

Esse projeto do Governo Federal, em conjunto com outros órgãos federais, é um instrumento do GERCO que resulta da ação entre o MMA e do Ministério do Planejamento, através da Secretaria de Patrimônio da União (SQA). O objetivo é o de ordenar os espaços litorâneos sob domínio da União, principalmente dos grandes centros urbanos, aproximando as políticas ambiental e patrimonial, com ampla articulação entre as três esferas de governo e a sociedade, buscando assim, uma gestão compartilhada da orla.

O principal objetivo do Projeto Orla em nível nacional consiste em:

Compatibilizar as políticas ambiental e patrimonial do governo federal no trato dos espaços litorâneos sob propriedade ou guarda da União, buscando, inicialmente, dar uma nova abordagem ao uso e gestão dos terrenos e acrescidos de marinha, como forma de consolidar uma orientação cooperativa e harmônica entre as ações e políticas praticadas na orla marítima (BRASIL, 2006, p. 7). 
| Maria Bonfim Casemiro | Otávio Augusto de Oliveira Lima Barra | Fábio Perdigão Vasconcelos | |Fábio de Oliveira Matos |

Visando atingir à meta principal, o Projeto Orla estabeleceu os seguintes objetivos específicos e estratégicos:

Fortalecer a capacidade de atuação e a articulação de diferentes atores do setor público e privado na gestão integrada da orla, aperfeiçoando o arcabouço normativo para o ordenamento de uso e ocupação desse espaço; desenvolver mecanismos institucionais de mobilização social para sua gestão integrada; estimular atividades socioeconômicas compatíveis com o desenvolvimento sustentável da orla (BRASIL, 2006, p. 07).

Através desses objetivos é possível perceber que o Projeto Orla destaca a necessidade de uma participação cidadã, bem como uma integração que deve existir entre os diferentes atores envolvidos no ambiente costeiro, tendo estes, muitas vezes, interesses convergentes. Os objetivos sinalizam a necessidade de compatibilização com as atividades econômicas existentes nesses espaços, uma vez que é fundamental para as bases do desenvolvimento sustentável. Em linhas gerais, significa dizer que o desenvolvimento econômico tem de ser estruturado e pensado dentro da lógica ambiental.

A questão do desenvolvimento sustentável envolve a escala da gestão municipal, tendo em vista que o Projeto Orla trabalha com o intuito de valorização da paisagem, dos atrativos turísticos e da proteção dos costumes existentes em determinadas localidades. Visa também à geração de pequenos negócios dados de forma menos impactante ao meio ambiente, em que seja possível compatibilizar a conservação do ambiente natural e, ao mesmo tempo, a utilização sustentável da biodiversidade local (BRASIL, 2006).

\section{Esferas de coordenação}

O Projeto Orla delega aos municípios o papel de elaboração do PGI (Plano de Gestão Integrada), este deve respeitar as normas e políticas (estadual e federal) vigentes. A esfera governamental municipal tem por responsabilidade a busca de financiamentos, bem como garantir a participação da sociedade na tomada de decisão, através de atividades sustentáveis locais, uma vez que a ferramenta valoriza, na elaboração de seus planos, o saber popular e o conhecimento local na busca de diálogos constantes em fóruns de atores municipais, tendo como interlocutor básico o poder local (BRASIL, 2006). O Projeto trabalha diretamente através da construção do conceito de orla definida como espaço restrito, não ultrapassando a escala horizontal de $10 \mathrm{~km}$, essa delimitação reduzida objetiva aproximar ao máximo possível a realidade local de aspectos físico-sociais e as relações dadas no espaço. 
| Planejamento ambiental costeiro no Brasil: um olhar crítico sobre o Projeto Orla |

| Maria Bonfim Casemiro | Otávio Augusto de Oliveira Lima Barra | Fábio Perdigão Vasconcelos | |Fábio de Oliveira Matos |

O arranjo institucional do Projeto Orla, apresentado na Figura 5, detalha as competências de cada instituição responsável pela legislação ambiental costeira que orientam a atuação. Os responsáveis pela coordenação nacional do projeto são representantes do Ministério do Meio Ambiente (MMA, SQA), conjuntamente com o Ministério do Planejamento, Orçamento e Gestão (MPO) e Secretaria de Patrimônio da União (SPU), que possuem a responsabilidade de integrar políticas públicas articuladas com demais órgãos federais atuantes na zona costeira, especialmente em áreas de abrangência do Projeto Orla (BRASIL, 2005).

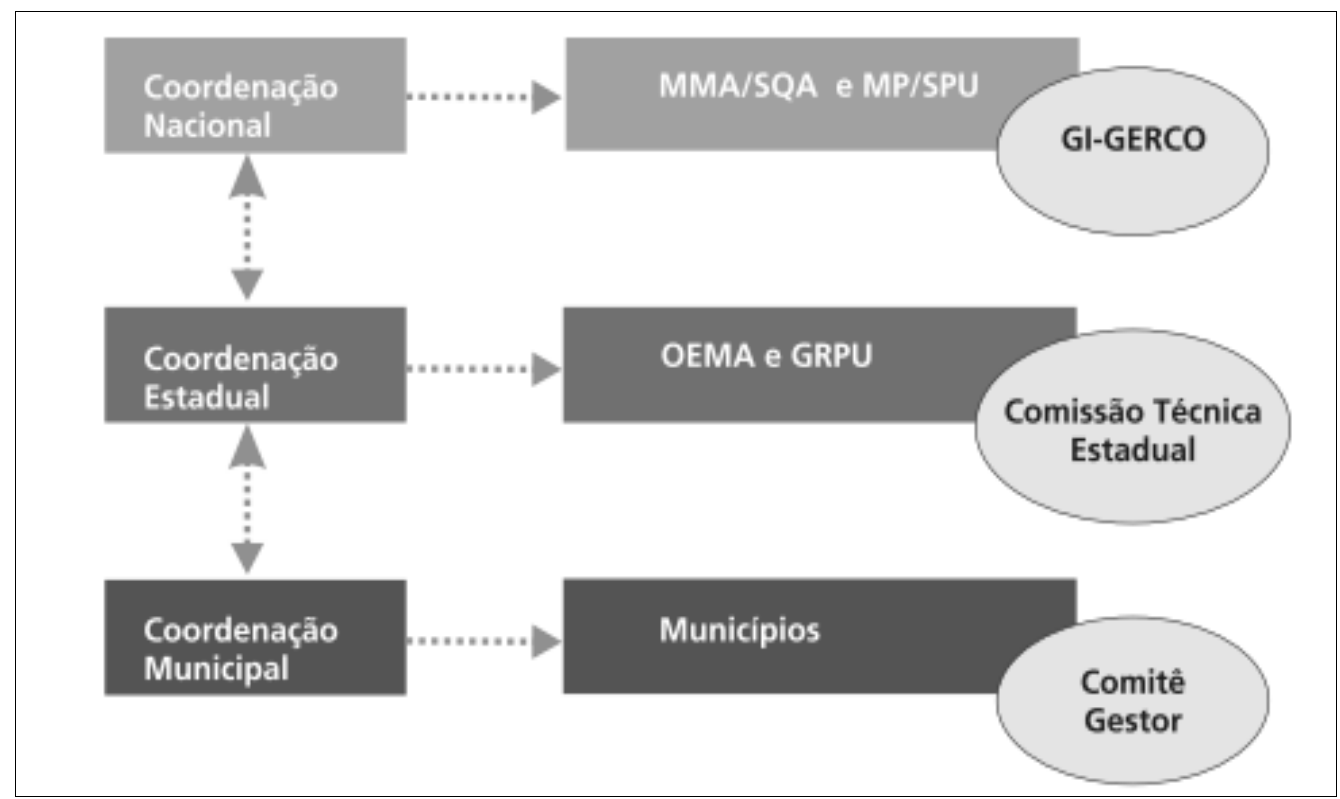

Figura 5 - Arranjo institucional do Projeto Orla

Fonte: Brasil (2005).

A Coordenação Estadual tem a responsabilidade de integrar as políticas ambientais costeiras no âmbito estadual, implementando e acompanhando o Projeto Orla É função daquela coordenação receber as propostas de adesão, selecionando os municípios inscritos para elaborarem seus PGI's, sendo formada pelos Órgãos Estaduais de Meio Ambiente (OEMA) e as Gerências Regionais do Patrimônio da União (GRPU), funciona em nível de cada estado (BRASIL, 2005).

A responsabilidade da Coordenação Municipal, por meio da Prefeitura, é na execução local do Projeto. Essa esfera e os parceiros locais devem organizar documentos técnicos, cartográficos e outros materiais que auxiliem na caracterização ambiental e socioeconômica da orla (BRASIL, 2005). O Decreto $n^{\circ}$. 5300, do art. 14, capítulo IV, cita que a esfera municipal é fundamental na promoção e no fortalecimento das entidades diretamente envolvidas no gerenciamento costeiro, através de apoio técnico, financeiro e 
| Maria Bonfim Casemiro | Otávio Augusto de Oliveira Lima Barra | Fábio Perdigão Vasconcelos | |Fábio de Oliveira Matos |

metodológico (BRASIL, 2004). Nessa esfera municipal, o Projeto Orla, de fato, se mantém, sendo a gestão que mais se aproxima da realidade local da área de estudo, pois, no município os problemas são mais latentes. É nessa esfera, também, que ocorre a elaboração do Plano de Gestão.

Junto à gestão integrada da zona costeira os Órgãos Colegiados, formados por membros do GI-GERCO, representantes da esfera nacional e da Comissão Técnica Estadual (CTE), auxiliam as coordenações nacionais, estaduais e municipais, bem como os estados e o Comitê Gestor da Orla da administração municipal. Esse Comitê deve ser consultivo e deliberativo, com uma gestão participativa, o que, em síntese, significa dizer que estão envolvidos representantes dos órgãos públicos do município e da sociedade civil organizada, tendo representantes de órgãos federais e estaduais (BRASIL, 2005).

\section{Implementação}

O Projeto Orla propõe para a gestão da orla marítima a elaboração de um Plano de Intervenção (recentemente essa nomenclatura foi modificada para Plano de Gestão, pois, de acordo com alguns documentos, o núcleo do tipo do verbo intervir dava a ideia algo impositivo). Assim, um instrumento de gestão deve ser embasado no reconhecimento das características naturais, nos tipos de uso e ocupação existentes e projetados, de forma a contemplar a caracterização socioambiental, a classificação e estabelecer diretrizes para intervenção. O plano deve, necessariamente, definir ações articuladas de forma participativa, a partir da construção de cenários de uso e ocupação, de caráter normativo, gerencial ou executivo.

De forma geral, o Projeto Orla trabalha inicialmente com a divisão da orla municipal em unidades, geralmente determinadas em função da urbanização, em que cada unidade é separada por vários trechos. Estes são determinados em função das características semelhantes do ambiente, a partir dessa divisão são escolhidos dois trechos em função da paisagem similar que necessite de um estudo mais urgente. A proposta de delimitação adotada pelo Projeto Orla para a elaboração dos planos de intervenção na orla marítima é realizada a partir de critérios de fragilidade ou de vulnerabilidade natural, envolve, também, as situações e os ritmos de ocupação que ocorrem no litoral brasileiro. Sendo assim, é estabelecida uma faixa específica para a gestão da orla, visando à manutenção das características paisagísticas (BRASIL, 2004). 
| Maria Bonfim Casemiro | Otávio Augusto de Oliveira Lima Barra | Fábio Perdigão Vasconcelos | |Fábio de Oliveira Matos |

A metodologia do Projeto Orla consiste na composição e na justaposição de cenários atuais, bem como na previsibilidade dos possíveis de ocorrer. Nesse sentido, na construção de um cenário é necessário verificar quais tipos de usos são praticados para que, a partir de cada situação indesejável de uso do espaço, seja possível elaborar uma situação desejada com resultado exitoso. Assim, esse cenário passa a ser uma meta e um objetivo a serem atingidos no processo de gestão, devendo ser detalhados e executados por ações elaboradas a partir de um Plano de Gestão na orla (BRASIL, 2006).

Nesse sentido, os cenários procuram representar as situações atuais em que se encontram a orla, as tendências do ambiente, caso não haja intervenção, e a situação desejada como forma de minimizar os problemas, através de orientações dadas ao poder público para a tomada gestão, ou seja, são apresentadas aos gestores propostas de procedimentos fundamentais e analíticos de compromisso local. A situação tendencial geralmente é a que se concretiza em caso de omissão por parte do gestor municipal. O método de trabalho do Projeto Orla para elaboração do PGI com bases na Gestão Integrada das Zonas Costeiras consiste nas seguintes etapas desenvolvidas em conjunto.

$\mathrm{Na}$ primeira etapa, é realizada a caracterização da área de determinada orla que necessite de melhor gestão, ou seja, é feito o reconhecimento das principais tendências dos processos dinâmicos naturais sejam eles: erosivos, hidrológicos, geológicos, geomorfológicos ou socioeconômicos. Essa ação tem como objetivo avaliar o padrão de ocupação existente, projetando o comportamento futuro e o resultado dessa ação (BRASIL, 2006).

A segunda etapa consiste na delimitação da área a ser contemplada pelo plano; essa ação apresentará uma visão espacial para a área em planejamento. É o momento em que deve ser feita a identificação das praias existentes no local, que, enquanto espaços públicos, de uso comum do povo, segundo a legislação, não devem possuir limitações de acesso, esse elemento é fundamental a ser considerado (BRASIL, 2006).

$\mathrm{Na}$ terceira etapa, é realizada a divisão, a caracterização dos trechos da orla e o levantamento de informações mais detalhadas da etapa. Em cada trecho da orla as informações principais serão as de cobertura predominante, padrão de urbanização e impactos visíveis na paisagem. A partir desses dados, é possível estabelecer e analisar o tipo de orla para uma posterior gestão integrada, quais sejam: abrigada, semiabrigada ou exposta. Os dados obtidos nessa etapa consistem em uma síntese dos processos que foram observados durante os trabalhos realizados em campo. A caracterização dos trechos 
| Planejamento ambiental costeiro no Brasil: um olhar crítico sobre o Projeto Orla |

| Maria Bonfim Casemiro | Otávio Augusto de Oliveira Lima Barra | Fábio Perdigão Vasconcelos | |Fábio de Oliveira Matos |

apresentará claramente os problemas identificados na área de planejamento (BRASIL, 2004).

Conforme Moraes (2007), o Projeto Orla adotou um modelo de gestão centralizado na ação local, incorporando em sua implantação os atores sociais inseridos no espaço de intervenção. Nesse sentido, foi elaborado um planejamento participativo que não desconsidera os conflitos sociais existentes. Para o autor, o objetivo maior foi o de envolver a sociedade, enquanto atores sociais, e adotar os interesses destes no processo de planejamento, a partir de escalas menores, como os municípios.

A discussão primordial deste trabalho consiste, sobretudo, no destaque da gestão proposta pelo Projeto Orla, tendo em vista o caráter integrado de planejamento e execução, que ultrapassam os limites puramente administrativos. Em síntese, significa dizer que toda e qualquer ação realizada em determinado espaço local, a exemplo do município, terá reflexo em áreas adjacentes, dada a dinâmica e interação dos ambientes costeiros.

O Plano de Intervenção (produto final do Projeto Orla) propõe a elaboração de bases para uma gestão ambiental integrada das áreas litorâneas, apresentando os problemas socioambientais, considerando sempre a integração entre poder público e sociedade civil organizada e incorporando a cultura de desenvolvimento sustentável com enfoque no desenvolvimento local e participação da sociedade no planejamento.

Em síntese, o Plano é um instrumento de planejamento e gestão, resultado das atividades realizadas a partir do diagnóstico e da classificação da orla, elaborado em etapas anteriores por agentes executivos do Projeto Orla, e da construção dos cenários atuais, tendenciais e desejados da área, elaborados por vários representantes da sociedade, após capacitação. Neste documento, são encontradas as estratégias que o poder público municipal deverá adotar para executar a gestão desse espaço, detalhando e justificando as atividades a serem desenvolvidas.

Os diagnósticos paisagísticos são importantes ferramentas de auxílio no momento de caracterização da área. A partir dos estudos das características e elementos da paisagem, é possível analisar as características físicas do ambiente, assim como as atividades econômicas e as intervenções antrópicas que exercem influência nas componentes do ambiente avaliado. Essa identificação do ambiente do ponto de vista paisagístico (em que se consideram as ações humanas e as características físico-ambientais) possibilita o reconhecimento da situação social, econômica e política vigentes, permite, ainda, entender a dinâmica social que resulta no processo de transformação do ambiente, a partir das diferentes formas de usos e ocupação dos recursos naturais locais (BRASIL, 2006). 
| Planejamento ambiental costeiro no Brasil: um olhar crítico sobre o Projeto Orla |

| Maria Bonfim Casemiro | Otávio Augusto de Oliveira Lima Barra | Fábio Perdigão Vasconcelos | |Fábio de Oliveira Matos |

A proposta de delimitação adotada pelo Projeto Orla (em uma escala pequena de grandes detalhes) "buscou combinar os critérios de fragilidade e/ou vulnerabilidade natural com as situações e ritmos de ocupação ocorrentes no litoral brasileiro” (BRASIL, 2004, p. 7).

\section{CONSIDERAÇÕES FINAIS}

A partir do exposto pode-se dizer que, de forma geral, as leis de gerenciamento costeiro constituem importantes instrumentos de orientação às ações de suporte ao poder público. É preciso salientar que esse gerenciamento costeiro deve de ser realizado de forma o mais integrado possível, buscando sempre envolver todas as dimensões geográficas, como os municípios, os estados e o país, compreendendo o sistema litorâneo como um todo do ponto de vista físico e social.

Viu-se que a orientação da promoção de políticas de gestão do desenvolvimento integrado, que visam não apenas o desenvolvimento econômico de determinada região, mas a integração com a comunidade local é seguida pelo Projeto Orla Marítima ao inserirse em uma perspectiva de gestão participativa, buscando sempre o envolvimento da população no processo de gestão.

Ficou claro que o Projeto Orla, objetivando ampliar as possibilidades de solução de conflitos de uso e reversão dos processos de degradação pela qual passam determinadas áreas litorâneas, permite que o uso desse espaço seja dado de forma adequada (portanto, sustentável); potencializando essa área como um elemento fundamental no desenvolvimento do turismo, valorizando as áreas de litoral enquanto espaço de convívio social e compatibilizando, assim, a conservação e a utilização sustentável do ambiente local.

Foi apontado que, ao trabalhar com uma escala bastante reduzida de trabalho, o Projeto inclui e valoriza, na elaboração de seus planos, o saber popular e o conhecimento local, objetivando aproximar ao máximo possível a realidade local dos aspectos sociais e físicos e as relações dadas nesse espaço de tamanha fragilidade, buscando diálogos constantes entre os fóruns de atores municipais, tendo no poder local o interlocutor básico. Sua metodologia de composição e justaposição de cenários atuais possibilita uma previsibilidade dos fatos possíveis de ocorrer, fato que torna possível a elaboração de uma situação desejada com resultado exitoso, em que o cenário passa a ser uma meta e um objetivo a serem atingidos no processo de gestão. 
| Maria Bonfim Casemiro | Otávio Augusto de Oliveira Lima Barra | Fábio Perdigão Vasconcelos | |Fábio de Oliveira Matos |

Em suma, o Projeto Orla constitui-se em uma ferramenta possível de ser executada no apoio à gestão, justamente por estar fundamentada na proposta de ferramenta de uma gestão integrada que valoriza a participação da sociedade no planejamento costeiro, devendo ser valorizada como tal. Assim, a análise de tal instrumento de gestão ambiental permitiu observar que consiste em peça importante às oportunidades de desenvolvimento da orla, pois, através da articulação entre os instrumentos de gestão existentes, os investimentos serão priorizados em áreas estratégicas de preservação ambiental. O dito pode resultar em políticas ambientais para o território municipal de forma mais efetiva.

Atualmente, com a Lei n. 13.240/2015, que transfere a gestão das praias da União para os municípios, o Projeto Orla passa a ser obrigatório, devendo o município, em até 3 (três) anos, elaborar o plano para ordenamento da Orla, em conformidade com o art. 32 do Decreto no 5.300, de 2004, ou revisão do plano já existente. Caso o Município se recuse a elaborar o Projeto Orla, estará sujeito a multa ou mesmo a rescisão do Termo de outorga por inadimplemento de cláusula.

\section{REFERÊNCIAS}

AGRA FILHO, Severino Soares. A gestão ambiental da zona costeira no Brasil: os desafios atuais. Revista Gestão Costeira Integrada, Santa Catarina, ano 4, n. 5, p. 23-24, 2006.

ALMEIDA, Patrícia Aparecida Pereira Souza de. Políticas ambientais e seus desdobramentos: o gerenciamento costeiro em debate. Revista Gestão Costeira Integrada, Santa Catarina, ano 4, n. 5, p. 39-42, 2006.

BRASIL. Constituição da República Federativa do Brasil. Brasília: Senado Federal, 1988.

Projeto Orla: Fundamentos para a Gestão Integrada. Brasília: Ministério do Meio Ambiente (MMA); Ministério do Planejamento, Orçamento e Gestão (MPO), 2006. 74 p.

Projeto Orla: Subsídios para um projeto de Gestão. Brasília: Ministério do Meio Ambiente (MMA); Ministério do Planejamento, Orçamento e Gestão (MPO), 2004. 104 p.

Projeto Orla: Guia de implementação. Brasília: Ministério do Meio ambiente (MMA); Ministério do Planejamento, Orçamento e Gestão (MPO), 2005. 36 p.

Lei $\mathrm{n}^{\mathbf{0}}$ 6938, de 31 de agosto de 1981. Dispõe sobre a Política Nacional do Meio Ambiente, seus fins e mecanismos de formulação e aplicação, e dá outras providências. Disponível em: < https://goo.gl/xfD72> . Acesso em: 20 fev. 2016.

Lei $\mathrm{n}^{\circ}$. 7.661, de 16 de maio de 1988. Dispõe sobre o Plano Nacional de Gerenciamento Costeiro - PNGC. Disponível em: <http://goo.gl/s9DUtr $>$. Acesso em: 20 jun. 2016. 
| Maria Bonfim Casemiro | Otávio Augusto de Oliveira Lima Barra | Fábio Perdigão Vasconcelos | |Fábio de Oliveira Matos|

Lei $\mathrm{n}^{\circ}$ 9.636, de 15 de maio de 1998. Dispõe sobre a regularização, administração, aforamento e alienação de bens imóveis de domínio da União. Disponível em: <http://www.planalto.gov.br/ccivil 03/leis/L9636.htm. Acesso em abril 2016>. Acesso em: 10 dez. 2016.

Lei complementar $\mathbf{N}^{\circ}$ 140, de 8 de dezembro de 2011. Fixa normas. Disponível em: < http://www.planalto.gov.br/ccivil 03/leis/LCP/Lcp140.htm>. Acesso em: 20 dez. 2016.

D.O.U. Decreto $\mathbf{n}^{\mathbf{0}}$. 5300, de 07 de dezembro de 2004. Regulamenta a Lei $\mathrm{n}^{\circ}$ 7.661, de 16 de maio de 1988, que institui o PNGC, dispõe sobre regras de uso e ocupação da zona costeira e estabelece critérios de gestão da orla marítima, e dá outras providências. Disponível em: < http://goo.gl/2XTZ9M>. Acesso em: 10 set. 2016.

CASEMIRO, M. B.; BARRA, O. A. O. L.; VASCONCELOS, F. P.; MATOS, F. O. Análise do Projeto Orla Marítima de Icapuí/CE na perspectiva dos gestores locais e ambientalistas. Caminhos de Geografia, v. 19, p. 361-374, 2018.

CICIN-SAIN, B.; KNECHT, R. W. Integrated coastal and ocean management: concepts and practices. Washington DC: Island Press, USA, 1998. 517 p.

DAVIDSON-ARNOTT, Robin. Introduction to coastal processes and geomorphology. New York: Cambridge University Press, 2010.

GERHARDT, Tatiana Engel; SILVEIRA Denise Tolfo (Org.). Métodos de pesquisa. Porto Alegre: Editora da UFGRS, 2009.

INSTITUTO BRASILEIRO DE GEOGRAFIA E ESTATÍSTICA. Atlas geográfico das zonas costeiras e oceânicas do Brasil. Rio de Janeiro: IBGE, 2011. 176 p.

MORAES, Antonio Carlos Robert. Contribuições para a gestão da zona costeira do Brasil: elementos para uma geografia do litoral brasileiro. São Paulo: Annablume, 2007.

OLSEN, Stephen B. Frameworks and indicators for assessing progress in integrated coastal management initiatives. Ocean e Coastal Management, v. 46, p. 347-361, 2003.

PEREIRA, Flávia Cabral; OLIVEIRA, Márcia Regina de (Org.). Plano Nacional de Gerenciamento Costeiro: 25 anos do gerenciamento costeiro no Brasil; Brasília: MMA, 2015.

PILATI, Luciana Cardoso; DANTAS, Marcelo Buzaglo; LEITE, José Rubens Morato (Coord.). Direito Ambiental Simplificado. São Paulo: Saraiva, 2011.

POLETTE, Marcus; REBOUÇAS, Gabriel Nunes Maia; FILARDI, Ana Carla Leão; VIEIRA, Paulo Freire. Rumo à gestão integrada e participativa de zonas costeiras no Brasil: percepções da comunidade científica e do terceiro setor. Revista Gestão Costeira Integrada, UNIVALI, ano 4, n. 5, p. 43-48, 2006.

SALES, Maria Tereza Bezerra Farias et al. A conservação da paisagem e da biodiversidade. In: MONTEIRO, Andreia Quandt; MONTEIRO NETO, Cassiano; POLETTE, Marcus 
| Maria Bonfim Casemiro | Otávio Augusto de Oliveira Lima Barra | Fábio Perdigão Vasconcelos | |Fábio de Oliveira Matos|

(Coord.). A zona costeira do Ceará: diagnóstico para a gestão integrada. Fortaleza: Associação de Pesquisa de Preservação e Ecossistemas, 2003. p. 84-107.

SOUZA, Celia Regina de Gouveia. A erosão costeira e os desafios da gestão costeira no Brasil. Revista da Gestão Costeira Integrada, UNIVALI, v. 9, n. 1, p. 17-37, 2009.

VASCONCELOS, Fábio Perdigão. Gestão Integrada da Zona Costeira: ocupação antrópica desordenada, erosão, assoreamento e poluição ambiental do litoral. Fortaleza: Premius, 2005. 